\title{
Normal Salivary Cortisol and NK Cell Function in Adolescents With Chronic Fatigue Syndrome Following Infectious Mononucleosis
}

\author{
Ben Z Katz ${ }^{1,2,}$, Donald Zimmerman ${ }^{1,2}$, Maurice RG Gorman ${ }^{2,3,4}$, Cynthia J Mears ${ }^{1,2}$, Yukiko \\ Shiraishi ${ }^{5}$, Renee Taylor ${ }^{5}$ \\ ${ }_{2}^{1}$ Department of Pediatrics, School of Medicine, Northwestern University, Chicago, USA \\ ${ }_{3}^{2}$ Feinberg and the Ann and Robert H. Lurie Children's Hospital of Chicago, Chicago, USA \\ ${ }^{3}$ Department of Pathology, School of Medicine, Northwestern University, Chicago, USA \\ 4 Department of Occupational Health, Northwestern University, Chicago, USA \\ ${ }^{5}$ College of Applied Sciences, University of Illinois, Chicago, USA \\ *Corresponding author: Ben Z. Katz, Division of Infectious Disease, Ann and Robert H Lurie Children's Hospital of Chicago, 225 E Chicago Ave., Box 20, Chicago, USA. Tel: +1-3122274080, \\ Fax:+1-3122279709, E-mail: bkatz@northwesterns.edu.
}

Received: June 21, 2013; Revised: August 16, 2013; Accepted: October 19, 2013

\begin{abstract}
Background: Chronic fatigue syndrome (CFS) is a complex condition involving severe fatigue and disabling musculoskeletal and cognitive symptoms. We reported that 6,12 and 24 months following infectious mononucleosis (IM), $13 \%, 7 \%$ and $4 \%$ of adolescents, respectively, met criteria for CFS. Whether endocrinologic or immunologic dysfunction accompanies CFS is unclear.

Objectives: To determine if salivary cortisol levels or NK cell percentage and function 6, 12 and 24 months following IM in adolescents who met criteria for CFS and recovered, matched controls differ.

Patients and Methods: Nine adolescents with CFS and nine matched, recovered controls had morning and nighttime salivary cortisol as well as NK cell number and function measured blindly 6,12 and 24 months following IM.

Results: Three subjects with CFS had a depressed morning salivary cortisol; one control subject had a single depressed nighttime cortisol. There was no difference in NK cell percentage or decreased function between cases and recovered controls.

Conclusions: We found little evidence of depressed salivary cortisol levels and no decreased NK cell function in adolescents with CFS following IM.
\end{abstract}

Keywords: Fatigue Syndrome, Chronic; Infectious Mononucleosis; Killer Cells, Natural; Hydrocortisone

\section{Background}

Chronic fatigue syndrome (CFS) is a complex condition involving at least 6 months of severe fatigue and disabling musculoskeletal and cognitive symptoms (impairment in short-term memory or concentration, headache, tender lymphadenopathy, muscle or joint pain, unrefreshed sleep and post-exertional malaise lasting $>24$ hours) without another explanation (1). Anywhere from about $25-90 \%$ of adolescent patients with CFS can identify a trigger, often an infection (2). Chronic fatigue accounts for marked functional impairment and educational disruption among adolescents $(3,4)$.

In adults, about $10 \%$ of individuals meet the criteria for CFS 6 months following infectious mononucleosis (IM) (5-7). We recently reported that 6,12 and 24 months following infectious mononucleosis (IM), 13\%, 7\% and $4 \%$ of adolescents, respectively, met criteria for CFS (8). Previous reports from this cohort examined peak work capacity (9), orthostatic intolerance (10), activity level (11) autonomic system complaints (12) and cytokines (13). The current report concerns serial measurements of endocrinologic and immunologic function.

Whether hypothalamic-pituitary-adrenal (HPA) axis abnormalities or subtle immune deficits accompany CFS is controversial. The HPA axis is activated by stress, Addison's disease can cause a clinical picture similar to CFS, and HPA dysregulation may be seen with depression. Of all the immunological parameters studied in patients with CFS, NK cell abnormalities are the most consistently reported (14), but even here results are not completely consistent; in fact, sometimes even the same groups do not obtain exactly the same results in different studies $(15,16)$. At least 7 groups have reported decreased NK cell activity in at least half of the patients with CFS studied (1524). In 2 studies the severity of fatigue correlated with the

Implication for health policy/practice/research/medical education:

We report prospectively collected data from our large clinical trial of chronic fatigue syndrome (CFS) following infectious mononucleosis (IM) in adolescents 24 months following the diagnosis of IM. We did not find evidence for depressed cortisol or natural killer cell number or function in adolescents with CFS compared with recovered controls, despite this being reported in the literature. Our negative findings are particularly important because of the carefully controlled way our large study was performed. While our numbers may appear small, we began with $>300$ subjects and followed those who developed CFS after IM for 2 years.

Copyright (C 2014, Pediartric Infections Research Center. This is an open-access article distributed under the terms of the Creative Commons Attribution License, which permits unrestricted use, distribution, and reproduction in any medium, provided the original work is properly cited. 
decreased NK cell activity $(17,20)$. In many of these studies, the percentage of NK cells was normal $(16,21-23)$. Two groups reported normal NK cell activity in patients with CFS $(25,26)$. Many of these studies used the older 1988 Holmes definition (27) for CFS $(15,18-20,25)$. One recent study reported longitudinal data (24), as did ours.

Salivary cortisol is a useful and reliable index of adrenocortical activity. Awakening is a mild stressor, and thus morning cortisol (which remains elevated for at least an hour) is an indicator of the responsiveness of the hypothalamic pituitary axis that is not affected by age, sleep duration, time of awakening, use of an alarm clock, smoking, or the use of contraceptives. Finally, salivary cortisol collection avoids the possibly confounding stress of venipuncture (28).

Previous studies in adults have reported mixed results regarding CFS and salivary cortisol: Two studies showed no differences between patients with CFS and matched controls $(29,30)$. One study could not show a relationship between fatigue following IM and salivary cortisol (31). Three studies showed decreased morning and/or evening salivary cortisol vs. controls $(28,32,33)$. In 1 study this was true only in females in the morning (34). One study showed decreased morning but increased evening cortisol vs. controls (35).

\section{Objectives}

We studied salivary cortisol and NK cell number and function in nine subjects who retained a diagnosis of CFS 6,12 and 24 months following IM for whom samples were available, and matched controls.

\section{Patients and Methods}

Nine of 11 adolescents with CFS diagnosed 6, 12 and 24 months following IM and 9 recovered controls matched for age, sex and Tanner stage had morning and nighttime salivary cortisol measured blindly at each time point. All subjects were instructed to obtain morning saliva within an hour of awakening at home, and the time the sample was obtained was recorded. Saliva was collected through passive drool into a test tube. The sample was then stored in the home freezer till pick up at which time it was put on ice, and stored in the study freezer until analysis. Laboratory workers were blinded to subject diagnosis. Cortisol was isolated with a solid phase extraction protocol using a Micromass Quattro Micro triple-quadrupole mass spectrometer equipped with a Z-spray ion source and a Waters 2795 Alliance HT HPLC system. The method was developed and validated in our hospital's clinical mass spectrometry laboratory, similar to a previously described method (36). Normal ranges are as follows for postpubertal subjects and adults: at $8 \mathrm{AM} 0.89-6.44 \mathrm{ng} /$ $\mathrm{mL}$, at 4 PM 0.31-1.61 ng/mL and at 11 PM 0-0.82 ng/mL. Assessments (normal, low and high) regarding the salivary cortisol measurements were made by an experienced pediatric endocrinologist blinded as to the clinical status of each patient, based on the time the sample was taken and its value.

These same nine adolescents with CFS 24 months following IM and 9 matched, recovered controls also had blood drawn for NK cell quantitation and functional analysis that was performed blinded at 6,12 and 24 months following IM. NK cell quantification and function were ascertained using flow cytometry with the \%CD56+ cells for NK cell number, and K562 cells in 3 different dilutions (1:50, 1:25 and 1:12.5) of patient lymphocytes; the percentage of killed K562 cells minus background was then calculated for NK cell function (37-39). Normal ranges are as follows: $\%$ CD56 = 2-12; \% killing 50:1 = 10-40, 25:1 = 5-30, 12.5:1 = 3-20. NK cell percentage and function was compared between cases and controls with statistical analysis software (SAS) 9.2 using least square means in the linear mixed model analysis. Matched analysis was also performed between case patients and his/her matched control.

This study was approved by the institutional review boards of both the Ann and Robert H Lurie Children's Hospital of Chicago (formerly Children's Memorial Hospital) and the University of Illinois at Chicago.

\section{Results}

We studied a population of patients with CFS following IM and matched, recovered controls. Briefly, 301 adolescents from the greater Chicago area with monospot+ IM were enrolled. Six months later 286 (95\%) completed a telephone screening interview. Seventy (24\%) were considered not fully recovered. Fifty-three of the $70(76 \%)$ were clinically evaluated. Thirty-nine (13\% of the 301) met the Fukuda criteria for CFS 6 months after IM, 22 (7\%) at 12 months and 13 (4\%) at 24 months, as determined by an expert panel; 11 of the latter 13 were diagnosed with CFS at all 3 time points. Fifty recovered adolescents willing to be clinically evaluated and followed for 18 months served as controls (8).

All patients with CFS and recovered controls were at least Tanner stage 4 . There were 46 evaluable salivary cortisol levels in the patients with CFS and 49 in the recovered controls. There were only 3 depressed morning salivary cortisols among the patients with CFS (and 6 elevated cortisols, 4 of which were nighttime). Among the recovered controls there was a single depressed nighttime cortisol (and 7 elevated cortisols, 3 of which were nighttime) (Tables 1 and 2). There was also no difference in the average morning and evening salivary cortisol at any time point between subjects with CFS and recovered controls (data not shown).

There were 27 NK cell quantitation and functional analysis data points for the CFS patients and 25 for the controls. There was no difference in NK cell percentages between 
Katz BZ et al.

\begin{tabular}{|c|c|c|c|c|c|c|}
\hline \multirow[t]{2}{*}{ Case Patients ${ }^{\mathrm{a}}$} & \multicolumn{2}{|c|}{6 Months } & \multicolumn{2}{|c|}{12 Months } & \multicolumn{2}{|c|}{24 Months } \\
\hline & AM & PM & AM & PM & $\mathbf{A M}$ & PM \\
\hline 37 & Normal $^{\mathrm{b}}$ & Normal & Normal & - & Normal & High \\
\hline 116 & High & Normal & - & - & Normal & Normal \\
\hline 161 & Normal & Normal & Normal & Normal & - & High \\
\hline 223 & Normal & Normal & Normal & Normal & Normal & High \\
\hline 228 & Normal & Normal & Low & Normal & Normal & Normal \\
\hline 240 & - & -- & Normal & Normal & Normal & Normal \\
\hline 242 & Normal & Normal & Low & High & Normal & Normal \\
\hline 277 & Low & High & Normal & Normal & Normal & Normal \\
\hline 295 & - & -- & Normal & Normal & Normal & Normal \\
\hline
\end{tabular}

$\mathrm{a}$ The first column represents their unique ID study numbers.

$\mathrm{b}$ Normal ranges are as follows for postpubertal subjects and adults: at 8 AM 0.89-6.44 ng/mL, at 4 PM 0.31-1.61 ng/mL and at 11 PM 0-0.82 ng/mL.

Table 2. Salivary Cortisols 6, 12 and 24 Months Following IM in Recovered Controls

\begin{tabular}{lllllll}
\hline Case Patients $^{\text {a }}$ & \multicolumn{2}{c}{ 6 Months } & \multicolumn{2}{c}{ 12 Months } & 24 Months \\
\hline $\mathbf{4 2}$ & AM & PM & AM & PM & AM & PM \\
$\mathbf{9 1}$ & Normal $^{\text {b }}$ & High & Normal & Normal & Normal & High \\
$\mathbf{3 8 0}$ & - & Normal & Normal & Normal & Normal & Normal \\
$\mathbf{3 0 1}$ & Normal & High & Normal & Normal & Normal & High \\
$\mathbf{4 1 4}$ & High & Normal & Normal & Normal & Normal & Normal \\
$\mathbf{3 8 2}$ & Normal & Normal & High & Normal & Normal & Normal \\
$\mathbf{1 5 2}$ & -- & -- & Normal & High & Normal & Normal \\
$\mathbf{4 0 2}$ & Normal & -- & High & -- & Normal & Normal \\
$\mathbf{3 9 1}$ & Normal & Normal & High & Normal & Normal & Normal \\
\hline
\end{tabular}

$\mathrm{a}$ The first column represents their unique ID study numbers.

$\mathrm{b}$ Normal ranges are as follows for postpubertal subjects and adults: at 8 AM 0.89-6.44 ng/mL, at 4 PM 0.31-1.61 ng/mL and at 11 PM 0-0.82 ng/mL.

cases and recovered controls at any of the 3 time points examined (Table 3). NK function was significantly higher in case patients with CFS 6 months following IM than in recovered controls at 6,12 or 24 months $(P=0.02$; Table 4$)$. Matched analysis yielded similar results (data not shown).

\section{Discussion}

We found no evidence of consistently depressed salivary cortisol levels in adolescents with CFS following IM compared with recovered controls. While we cannot rule out depressed salivary cortisol as an uncommon cause of CFS, it cannot be the only cause, and does not persist despite the persistence of symptoms. These data are consistent with clinical trials demonstrating little if any benefit from cortisol replacement therapy in CFS (40-45) as well as our previous data regarding salivary cortisol during exercise (9).
Unlike many previous studies, we did not find decreased NK cell function in our prospective cohort of adolescents with CFS defined by the Fukuda criteria following IM when cases were compared with recovered controls; in fact, NK function was significantly higher in case patients with CFS 6 months following IM than in recovered controls, for unclear reasons. A recent longitudinal study in adults did for the most part show decreased NK cell

Table 3. Median NK Cell Percentage in Case Patients and Recovered Controls 6, 12 and 24 Months Following IM ${ }^{\mathrm{a}}$

\begin{tabular}{llll}
\hline & Cases & Controls & P Value \\
\hline 6 Months & $4.1(n=9)$ & $4.7(n=8)$ & 0.3417 \\
12 Months & $5.8(n=9)$ & $8.18(n=8)$ & 0.8833 \\
24 Months & $5.5(n=9)$ & $7.8(n=9)$ & 0.9728 \\
\hline
\end{tabular}

${ }^{a}$ Normal range for $\%$ CD56 $=2-12$. 
Katz BZ et al.

\begin{tabular}{|c|c|c|c|c|}
\hline Time Point & Dilution & CFS Cases, No. (\%) & Controls, No. (\%) & PValue \\
\hline \multicolumn{5}{|l|}{6 Months } \\
\hline & $50: 1$ & $22.8(\mathrm{n}=9)$ & $14.3(\mathrm{n}=8)$ & 0.0011 \\
\hline & $25: 1$ & $14.2(n=9)$ & $8.3(\mathrm{n}=8)$ & 0.0011 \\
\hline & 12.5:1 & $10.9(n=9)$ & $3.6(\mathrm{n}=8)$ & 0.0011 \\
\hline \multicolumn{5}{|l|}{12 Months } \\
\hline & $50: 1$ & $12.8(\mathrm{n}=9)$ & $17.5(\mathrm{n}=8)$ & 0.0801 \\
\hline & $25: 1$ & $6.9(\mathrm{n}=9)$ & $10(n=8)$ & 0.0801 \\
\hline & 12.5:1 & $3.4(\mathrm{n}=9)$ & $6.0(n=8)$ & 0.0801 \\
\hline \multicolumn{5}{|l|}{24 Months } \\
\hline & $50: 1$ & $18.1(n=9)$ & $16.6(n=9)$ & 0.7749 \\
\hline & $25: 1$ & $10.7(\mathrm{n}=9)$ & $10.2(\mathrm{n}=9)$ & 0.7749 \\
\hline & 12.5:1 & $6.2(n=9)$ & $5.6(n=9)$ & 0.7749 \\
\hline
\end{tabular}

${ }^{a}$ Normal range for \% killing at each dilution are as follows: 50:1 = 10-40, $25: 1=5-30,12 \cdot 5: 1=3-20$.

activity over time in subjects with CFS (24). Besides the fact that we studied adolescents following a uniform, known trigger (IM), the control groups in the 2 studies also differed, perhaps explaining the differing results; we used recovered controls, while Brenu et al. (24) utilized healthy controls.

One limitation of our study is the fact that we have a relatively small number of subjects and matched controls. However, that is because of the study's prospective design, beginning with $>300$ adolescents. A much larger prospective study would be necessary to obtain a much larger sample than was available to us. Nevertheless, the availability of adolescents with persistent complaints diagnosed as CFS up to 24 months following IM is a valuable resource. The fact that we found higher NK function at 6 months among case patients makes it extremely unlikely that adolescents with CFS following IM actually have depressed immune function.

Many of the previous reports from this CFS cohort concentrated on differences between those adolescents who developed CFS 6 months following IM and recovered controls; for example, we saw no differences in peak work capacity or orthostatic intolerance 6 months following IM between cases and recovered controls $(9,10)$. In the current study, we studied adolescents who maintained the diagnosis of CFS at all 3 evaluated time points $(6,12$ and 24 months following IM), and we did not see differences in NK cell percentage or function nor in AM or PM salivary cortisol levels 6,12 or 24 months following IM between case patients and recovered controls, which contrasts with the significant differences we observed when examining activity level (11) autonomic system complaints (12) and a network of cytokines (13); whether these latter findings are causes or effects of CFS is unknown. We are plan- ning a prospective study of university students to resolve some of these issues.

\section{Acknowledgements}

The authors had full access to all the data in the study and take responsibility for the integrity of the data and the accuracy of the data analysis. We thank all of the Clinical Research Center study nurses who helped us with the study and the Pediatric Practice Research Group, Shannon Haymond for help with salivary cortisol methodology, Deli Wang for statistical assistance and all of the physicians and school nurses who referred patients into our study.

\section{Authors' Contribution}

Drs. Katz, O'Gorman and Taylor designed the study. Drs. Katz and Mears examined all the patients. Dr. Shiraishi was responsible for database management. Drs. Katz, Zimmerman, O'Gorman, Shiraishi and Taylor analyzed the data. Dr. Katz wrote the first draft of the manuscript. All authors have seen and agree to the final form of the manuscript as submitted.

\section{Financial Disclosure}

The sponsor had no role in study design, data analysis or manuscript preparation.

\section{Funding/Support}

Supported by R 01 HD 4330101A1 from the National Institutes of Child Health and Human Development.

\section{References}

1. Fukuda K, Straus SE, Hickie I, Sharpe MC, Dobbins JG, Komaroff A. 
The chronic fatigue syndrome: a comprehensive approach to its definition and study. International Chronic Fatigue Syndrome Study Group. Ann Intern Med.1994;121(12):953-9.

2. Katz BZ, Jason LA. Chronic fatigue syndrome following infections in adolescents. Curr Opin Pediatr. 2013;25(1):95-102.

3. Richards J, Turk J, White S. Children and adolescents with Chronic Fatigue Syndrome in non-specialist settings: beliefs, functional impairment and psychiatric disturbance. Eur Child Adolesc Psychiatry. 2005;14(6):310-8.

4. ter Wolbeek M, van Doornen LJ, Kavelaars A, Heijnen CJ. Severe fatigue in adolescents: a common phenomenon? Pediatrics. 2006;117(6):e1078-86.

5. White PD, Thomas JM, Amess J, Crawford DH, Grover SA, Kangro $\mathrm{HO}$, et al. Incidence, risk and prognosis of acute and chronic fatigue syndromes and psychiatric disorders after glandular fever. BrJ Psychiatry. 1998;173:475-81.

6. Buchwald DS, Rea TD, Katon WI, Russo JE, Ashley RL. Acute infectious mononucleosis: characteristics of patients who report failure to recover. Am J Med. 2000;109(7):531-7.

7. Hickie I, Davenport T, Wakefield D, Vollmer-Conna U, Cameron B, Vernon SD, et al. Post-infective and chronic fatigue syndromes precipitated by viral and non-viral pathogens: prospective cohort study. BMJ. 2006;333(7568):575.

8. Katz BZ, Shiraishi Y, Mears CJ, Binns HJ, Taylor R. Chronic fatigue syndrome after infectious mononucleosis in adolescents. Pediatrics. 2009;124(1):189-93.

9. Katz BZ, Boas S, Shiraishi Y, Mears CI, Taylor R. Exercise tolerance testing in a prospective cohort of adolescents with chronic fatigue syndrome and recovered controls following infectious mononucleosis. JPediatr. 2010;157(3):468-72.

10. Katz BZ, Stewart JM, Shiraishi Y, Mears CJ, Taylor R. Orthostatic tolerance testing in a prospective cohort of adolescents with chronic fatigue syndrome and recovered controls following infectious mononucleosis. Clin Pediatr (Phila). 2012;51(9):835-9.

11. Huang Y, Katz BZ, Mears C, Kielhofner GW, Taylor R. Postinfectious fatigue in adolescents and physical activity. Arch Pediatr Adolesc Med. 2010;164(9):803-9.

12. Katz BZ, Stewart JM, Shiraishi Y, Mears CJ, Taylor R. Autonomic symptoms at baseline and following infectious mononucleosis in a prospective cohort of adolescents. Arch Pediatr Adolesc Med. 2011;165(8):765-6

13. Broderick G, Katz BZ, Fernandes $H$, Fletcher MA, Klimas N, Smith FA, et al. Cytokine expression profiles of immune imbalance in post-mononucleosis chronic fatigue. J Transl Med. 2012;10:191.

14. Bansal AS, Bradley AS, Bishop KN, Kiani-Alikhan S, Ford B. Chronic fatigue syndrome, the immune system and viral infection. Brain Behav Immun. 2012;26(1):24-31

15. Klimas NG, Salvato FR, Morgan R, Fletcher MA. Immunologic abnormalities in chronic fatigue syndrome. J Clin Microbiol. 1990;28(6):1403-10.

16. Fletcher MA, Zeng XR, Maher K, Levis S, Hurwitz B, Antoni M, et al. Biomarkers in chronic fatigue syndrome: evaluation of natural killer cell function and dipeptidyl peptidase IV/CD26. PLoS One. 2010;5(5):e10817.

17. Siegel SD, Antoni MH, Fletcher MA, Maher K, Segota MC, Klimas N Impaired natural immunity, cognitive dysfunction, and physical symptoms in patients with chronic fatigue syndrome: preliminary evidence for a subgroup? JPsychosom Res. 2006;60(6):559-66.

18. Tirelli V, Pinto A, Marotta G, Crovato M, Quaia M, De Paoli P, et al. Clinical and immunologic study of 205 patients with chronic fatigue syndrome: a case series from Italy. Arch Intern Med. 1993;153(1):116-7.

19. Barker E, Fujimura SF, Fadem MB, Landay AL, Levy JA. Immunologic abnormalities associated with chronic fatigue syndrome. Clin Infect Dis. 1994;18 Suppl 1:S136-41.

20. Ojo-Amaize EA, Conley EJ, Peter JB. Decreased natural killer cell activity is associated with severity of chronic fatigue immune dysfunction syndrome. Clin Infect Dis. 1994;18 Suppl 1:S157-9.

21. Masuda A, Nozoe SI, Matsuyama T, Tanaka H. Psychobehavioral and immunological characteristics of adult people with chronic fatigue and patients with chronic fatigue syndrome. Psychosom
Med.1994;56(6):512-8.

22. Levine PH, Whiteside TL, Friberg D, Bryant J, Colclough G, Herberman RB. Dysfunction of natural killer activity in a family with chronic fatigue syndrome. Clin Immunol Immunopathol. 1998;88(1):96-104.

23. Brenu EW, Staines DR, Baskurt OK, Ashton KJ, Ramos SB, Christy $\mathrm{RM}$, et al. Immune and hemorheological changes in chronic fatigue syndrome. J Transl Med. 2010;8:1.

24. Brenu EW, van Driel ML, Staines DR, Ashton KJ, Hardcastle SL, Keane J, et al. Longitudinal investigation of natural killer cells and cytokines in chronic fatigue syndrome/myalgic encephalomyelitis. J Transl Med. 2012;10:88.

25. Rasmussen AK, Nielsen H, Andersen V, Barington T, Bendtzen K, Hansen MB, et al. Chronic fatigue syndrome--a controlled cross sectional study. J Rheumatol.1994;21(8):1527-31.

26. Mawle AC, Nisenbaum R, Dobbins JG, Gary HE, Jr, Stewart JA, Reyes $\mathrm{M}$, et al. Immune responses associated with chronic fatigue syndrome: a case-control study.J Infect Dis. 1997;175(1):136-41.

27. Holmes GP, Kaplan JE, Gantz NM, Komaroff AL, Schonberger LB Straus SE, et al. Chronic fatigue syndrome: a working case definition. Ann Intern Med. 1988;108(3):387-9.

28. Roberts AD, Wessely S, Chalder T, Papadopoulos A, Cleare AJ. Salivary cortisol response to awakening in chronic fatigue syndrome. Br J Psychiatry. 2004;184:136-41.

29. Wood B, Wessely S, Papadopoulos A, Poon L, Checkley S. Salivary cortisol profiles in chronic fatigue syndrome. Neuropsychobiology. 1998;37(1):1-4.

30. Rahman K, Burton A, Galbraith S, Lloyd A, Vollmer-Conna U. Sleepwake behavior in chronic fatigue syndrome. Sleep. 2011;34(5):671-8.

31. Candy B, Chalder T, Cleare AJ, Peakman A, Skowera A, Wessely S, et al. Predictors of fatigue following the onset of infectious mononucleosis. Psychol Med. 2003;33(5):847-55.

32. Strickland P, Morriss R, Wearden A, Deakin B. A comparison of salivary cortisol in chronic fatigue syndrome, community depression and healthy controls. I Affect Disord. 1998;47(1-3):191-4.

33. Jerjes WK, Cleare AJ, Wessely S, Wood PJ, Taylor NF. Diurnal patterns of salivary cortisol and cortisone output in chronic fatigue syndrome. J Affect Disord. 2005;87(2-3):299-304

34. Nater UM, Maloney E, Boneva RS, Gurbaxani BM, Lin JM, Jones JF, et al. Attenuated morning salivary cortisol concentrations in a population-based study of persons with chronic fatigue syndrome and well controls. J Clin Endocrinol Metab. 2008;93(3):703-9.

35. Nater UM, Youngblood LS, Jones JF, Unger ER, Miller AH, Reeves WC, et al. Alterations in diurnal salivary cortisol rhythm in a population-based sample of cases with chronic fatigue syndrome. Psychosom Med. 2008;70(3):298-305.

36. Jonsson BA, Malmberg B, Amilon A, Helene Garde A, Orbaek P. Determination of cortisol in human saliva using liquid chromatography-electrospray tandem mass spectrometry. J Chromatogr $B$ Analyt Technol Biomed Life Sci. 2003;784(1):63-8.

37. Hatam L, Schuval S, Bonagura VR. Flow cytometric analysis of natural killer cell function as a clinical assay. Cytometry. 1994;16(1):59-68.

38. Whiteside TL. Measurement of NK-cell activity in humans. In: Rose NR, Hamilton RG, Detrick B s. Manual of Clinical Laboratory Immunology 6th edition. Washington: ASM Press;2002. p. 296-300.

39. Trinchieri G. Biology of natural killer cells. Adv Immunol. 1989;47:187-376.

40. McKenzie R, O'Fallon A, Dale J, Demitrack M, Sharma G, Deloria M, et al. Low-dose hydrocortisone for treatment of chronic fatigue syndrome: a randomized controlled trial.JAMA.1998;280(12):1061-6.

41. Peterson PK, Pheley A, Schroeppel J, Schenck C, Marshall P, Kind A, et al. A preliminary placebo-controlled crossover trial of fludrocortisone for chronic fatigue syndrome. Arch Intern Med. 1998;158(8):908-14.

42. Cleare AJ, Heap E, Malhi GS, Wessely S, O'Keane V, Miell J. Low-dose hydrocortisone in chronic fatigue syndrome: a randomised crossover trial. Lancet. 1999;353(9151):455-8.

43. Cleare AJ, Miell J, Heap E, Sookdeo S, Young L, Malhi GS, et al. Hypothalamo-pituitary-adrenal axis dysfunction in chronic fatigue syndrome, and the effects of low-dose hydrocortisone therapy. $J$ Clin Endocrinol Metab. 2001;86(8):3545-54. 
44. Blockmans D, Persoons P, Van Houdenhove B, Lejeune M, Bobbaers $\mathrm{H}$. Combination therapy with hydrocortisone and fludrocortisone does not improve symptoms in chronic fatigue syndrome: a randomized, placebo-controlled, double-blind, crossover study.
Am JMed. 2003;114(9):736-41.

45. Cleare AJ, O'Keane V, Miell JP. Levels of DHEA and DHEAS and responses to $\mathrm{CRH}$ stimulation and hydrocortisone treatment in chronic fatigue syndrome. Psychoneuroendocrinology. 2004;29(6):724-32. 